Pacific Journal of Mathematics

REGULARITY OF SOLUTIONS TO ELLIPTIC 


\title{
REGULARITY OF SOLUTIONS TO ELLIPTIC ISOPERIMETRIC PROBLEMS
}

\author{
HAROLD R. PARKS
}

\begin{abstract}
In an earlier paper by the author, the existence theory for solutions of elliptic isoperimetric problems was developed in the context of rectifiable and integral currents. The regularity problem for solutions of those isoperimetric problems was essentially left open. Examples were given to show that, in certain cases, regularity may be totally absent. In this note we derive positive regularity results for solutions of elliptic isoperimetric problems.
\end{abstract}

1. Introduction. Let $\Phi$ and $\Psi$ be class 2 elliptic integrands. The problem studied in $[\mathbf{P H}]$ was that of finding a surface, $S$, minimizing the integral of the integrand $\Phi$ over $S$ subject to the requirements that $S$ have a given boundary and that the integral of the integrand $\Psi$ over $S$ equal a specified value, $\psi$. In [PH] it was shown that two parameters, $\psi_{0}$ and $\psi_{1}$, were crucial to understanding the problem:

$\psi_{0}$ is the absolute minimum for the $\Psi$ integral among surfaces which satisfy the boundary condition, $\psi_{1}$ is the minimum for the $\Psi$ integral among surfaces which satisfy the boundary condition and for which the first variation of the $\Phi$ integral vanishes.

In this paper, also, $\psi_{0}$ and $\psi_{1}$ are crucial. Using the first variation to estimate the integrals over deformed surfaces, we are able to show that the regularity results of $\mathrm{F}$. J. Almgren, Jr., [AF], in the form recently derived by E. Bombieri, [BE], yield the following (see 6):

THEOREM. If $\psi_{0} \leq \psi<\psi_{1}$ and $T$ is a rectifiable current which minimizes the $\Phi$ integral among rectifiable currents which satisfy the boundary condition and have $\Psi$ integral equal to $\psi$, then the regular points are dense in spt $T \sim \operatorname{spt} \partial T$.

2. Preliminaries. We will use the notation and terminology of [PH]. Additionally, we

(1) assume $\Phi$ and $\Psi$ are class 2 elliptic integrands of degree $m$ on $Z$, 
(2) choose $\lambda$ with $1 \leq \lambda<\infty$ such that

$$
\begin{aligned}
& \lambda^{-1} \leq \Phi(z, \alpha) \leq \lambda \quad \text { and } \\
& \lambda^{-1} \leq \Psi(z, \alpha) \leq \lambda
\end{aligned}
$$

hold for $z \in A$ and $\alpha \in \wedge_{m} \mathbf{R}^{n}$ with $|\alpha|=1$,

(3) fix $\psi$ with $\psi_{0} \leq \psi<\psi_{1}$,

(4) fix $T \in \Re_{m, A}(Z)$ which satisfies $\operatorname{spt}(R-\partial T) \subset B,\langle\Psi, T\rangle=\psi$,

$$
\begin{aligned}
\langle\Phi, T\rangle=\inf \left\{\langle\Phi, S\rangle: S \in \mathcal{R}_{m, A}(Z),\right. & \\
& \operatorname{spt}(R-\partial S) \subset B,\langle\Psi, S\rangle=\psi\},
\end{aligned}
$$

(5) denote by $G$ the set of

$$
x \in(\text { Int } A \cap \operatorname{spt} T) \sim(B \cup \operatorname{spt} \partial T)
$$

such that there exist $r>0$ and a class 3 isotopic deformation

$$
h: I \times W \rightarrow Z \text {, }
$$

of an open subset, $W$, of $Z$ in $Z$, for $I$ an open interval with $0 \in I$, satisfying
(i) $A \subset W$,
(ii) $h(I \times \operatorname{spt} T) \subset A$,
(iii) $h[I \times(B \cap \operatorname{spt} \partial T)] \subset B$,
(iv) $h(t, z)=z$ for $t \in I$ and $z \in \mathbf{B}^{n}(x, r) \cup(\operatorname{spt} \partial T \sim B$ ),
(v) $h(t, z) \notin \mathbf{U}^{n}(x, r)$ for $t \in I$ and $z \notin \mathbf{U}^{n}(x, r)$,
(vi) $U^{n}(x, r) \subset$ Int $A \sim(B \cup$ spt $\partial T)$,
(vii) $\delta^{(1)}(T, \Phi, h) \neq 0$.

3. LEMMA. There is at most one point in

$$
[(\text { Int } A \cap \operatorname{spt} T) \sim(B \cup \operatorname{spt} \partial T)] \sim G .
$$

Proof. Fix

$$
\begin{aligned}
& x_{1} \in[(\text { Int } A \cap \operatorname{spt} T) \sim(B \cup \operatorname{spt} \partial T)] \sim G, \\
& x_{2} \in(\operatorname{Int} A \cap \operatorname{spt} T) \sim(B \cup \operatorname{spt} \partial T)
\end{aligned}
$$

with $x_{1} \neq x_{2}$. We will show

$$
x_{2} \in G \text {. }
$$

Since $\psi<\psi_{1}, T$ is not $\Phi$ stationary with respect to $(A, B)$ and, hence, there is a class 3 isotopic deformation 
of an open subset, $V$, of $Z$ in $Z$, for $J$ an open interval with $0 \in J$, satisfying

$$
\begin{aligned}
& A \subset V, \\
& k(J \times \operatorname{spt} T) \subset A, \\
& k[J \times(B \cap \operatorname{spt} \partial T)] \subset B, \\
& k(t, z)=z \text { for } t \in J \text { and } z \in \operatorname{spt} \partial T \sim B, \\
& \delta^{(1)}(T, \Phi, k) \neq 0 .
\end{aligned}
$$

Choose $r>0$ such that

$$
\mathbf{U}^{n}\left(x_{1}, 5 r\right) \subset \operatorname{Int} A \sim\left(\left\{x_{2}\right\} \cup B \cup \operatorname{spt} \partial T\right) .
$$

Choose an open interval $I$, with $0 \in I \subset J$, and an open $W$, with $A \subset W$ $\subset V$, such that

$$
\begin{gathered}
|k(t, z)-z|<r \quad \text { holds for } t \in I \text { and } z \in \mathbf{B}^{n}\left(x_{1}, 3 r\right), \\
k\left[I \times\left(W \sim \mathbf{U}^{n}\left(x_{1}, 2 r\right)\right)\right] \cap \mathbf{B}^{n}\left(x_{1}, r\right)=\varnothing
\end{gathered}
$$

Choose $\phi: \mathbf{R}^{n} \rightarrow \mathbf{R}$ of class $\infty$ such that

$$
\begin{aligned}
& \phi(z)=0 \text { if }|z| \leq 2 \\
& \phi(z)=1 \text { if }|z| \geq 3, \\
& 0 \leq \phi(z) \leq 1 \quad \text { for all } z \in \mathbf{R}^{n} .
\end{aligned}
$$

Define

$$
l: I \times W \rightarrow Z
$$

by setting

$$
l(t, z)=\phi\left(r^{-1}\left(z-x_{1}\right)\right) k(t, z)+\left(1-\phi\left(r^{-1}\left(z-x_{1}\right)\right)\right) z
$$

for $(t, z) \in I \times W$. We note that $r$ and $l$ satisfy the conditions $2(5 \mathrm{i}-\mathrm{vi})$ with $x$ replaced by $x_{1}$. Thus we have

$$
\delta^{(1)}(T, \Phi, l)=0 .
$$

Define

$$
h: I \times W \rightarrow Z
$$

by setting

$$
h(t, z)=\left(1-\phi\left(r^{-1}\left(z-x_{1}\right)\right)\right) k(t, z)+\phi\left(r^{-1}\left(z-x_{1}\right)\right) z
$$

for $(t, z) \in I \times W$. We have

$$
\begin{aligned}
0 & \neq \delta^{(1)}(T, \Phi, k) \\
& =\delta^{(1)}(T, \Phi, l)+\delta^{(1)}(T, \Phi, h)=\delta^{(1)}(T, \Phi, h) .
\end{aligned}
$$


Since $r$ and $h$ satisfy the conditions 2(5i-vi) with $x$ replaced by $x_{2}$, we have $x_{2} \in G$.

4.1. Preliminaries. In 4.2 we will use the following notation:

(1) Fix $x_{0} \in G$ and let $r_{0}>0$ and $h: I \times W \rightarrow Z$ satisfy the conditions of 2(5).

(2) Set

$$
\alpha=\delta^{(1)}(T, \Phi, h), \quad \beta=\delta^{(1)}(T, \Psi, h) .
$$

By hypothesis we have $\alpha \neq 0$, and without loss of generality we may assume $\alpha>0$.

(3) Define the elliptic integrand

$$
\Xi: Z \times \wedge_{m} \mathbf{R}^{n} \rightarrow \mathbf{R}
$$

by setting

$$
\Xi(z, \mu)=(|\alpha|+|\beta|)^{-1}[|\beta| \Phi(z, \mu)+|\alpha| \Psi(z, \mu)]
$$

for $(z, \mu) \in Z \times \wedge_{m} \mathbf{R}^{n}$.

4.2. THEOREM. There exist $r_{1}, c_{1}$, with $0<r_{1}, c_{1}<\infty$, such that for each $r$, with $0<r \leq r_{1}$,

$$
T \mathbf{L U}^{n}\left(x_{0}, r\right)
$$

is $(\Xi, \omega, 2 r)$ minimal in $\mathbf{U}^{n}\left(x_{0}, r\right)$ (see [BE; Definition 1$\left.]\right)$, where

$$
\omega(t)=c_{1} \sup \left\{\|T\| \mathbf{B}^{n}(x, t): x \in \mathbf{U}^{n}\left(x_{0}, r_{1}\right)\right\} .
$$

Proof. We will assume

$$
\delta^{(1)}(T, \Psi, h) \neq 0
$$

the proof in case $\delta^{(1)}(T, \Psi, h)=0$ is similar. By $[\mathbf{P H} ; 1.4]$ and the argument used in the proof of [PH; 1.3], we see that, in fact,

$$
\delta^{(1)}(T, \Psi, h)<0
$$

must hold.

We can find $\delta, c$, positive real numbers, and

$$
f, g: \mathbf{R} \cap\{t:|t|<\delta\} \rightarrow \mathbf{R} \cap\{t:|t|<c \delta\},
$$


of class 2, such that for $t$ with $|t|<\delta$ the following hold:

$$
\begin{gathered}
(1+c) t \in I, \\
\left|\left\langle\Phi, h_{t \#} T\right\rangle-\langle\Phi, T\rangle-t \delta^{(1)}(T, \Phi, h)\right| \leq c t^{2}, \\
\left|\left\langle\Psi, h_{t \#} T\right\rangle-\langle\Psi, T\rangle-t \delta^{(1)}(T, \Psi, h)\right| \leq c t^{2}, \\
\left\langle\Phi, h_{f(t) \#} T\right\rangle=\langle\Phi, T\rangle+t, \\
\left\langle\Psi, h_{g(t) \#} T\right\rangle=\langle\Psi, T\rangle+t, \\
\left|f(t)-t\left[\delta^{(1)}(T, \Phi, h)\right]^{-1}\right| \leq c t^{2}, \\
\left|g(t)-t\left[\delta^{(1)}(T, \Psi, h)\right]^{-1}\right| \leq c t^{2} .
\end{gathered}
$$

Let $r_{1}$ be such that

$$
0<r_{1} \leq 3^{-1} r_{0}, \quad\|T\| \mathbf{U}^{n}\left(x_{0}, 3 r_{1}\right)<\lambda^{-3} \delta .
$$

Set

$$
c_{1}=5 \lambda^{4}(1+\alpha)(1+|\beta|)\left(1+\alpha^{-1}\right)^{2}\left(1+|\beta|^{-1}\right)^{2}(1+\delta)^{2}(1+c)^{3} .
$$

Fix $r$ with $0<r \leq r_{1}$. Let $K$ be compact with $K \subset \mathbf{U}^{n}\left(x_{0}, r\right)$. Suppose $X \in \Re_{m}\left(\mathbf{R}^{n}\right)$ satisfies $\partial X=0$, spt $X \subset K$. Set $d=\operatorname{diam}($ spt $X)$ and fix $x_{1} \in \operatorname{spt} X$. By [PH; 1.4] and the argument used in the proof of [PH; 1.3], we may suppose either

$$
\langle\Psi, T\rangle\langle\langle\Psi, T+X\rangle, \quad\langle\Phi, T\rangle\rangle\langle\Phi, T+X\rangle
$$

or

$(* *)$

$$
\langle\Psi, T\rangle\rangle\langle\Psi, T+X\rangle, \quad\langle\Phi, T\rangle\langle\langle\Phi, T+X\rangle
$$

Case I. Assume (*) holds. We have

$$
\begin{aligned}
\langle\Psi, T+ & X\rangle-\langle\Psi, T\rangle \leq\left\langle\Psi,(T+X)\left\llcorner\mathbf{U}^{n}\left(x_{1}, d\right)\right\rangle\right. \\
& \leq \lambda\|T+X\| \mathbf{U}^{n}\left(x_{1}, d\right) \leq \lambda^{2}\left\langle\Phi,(T+X)\left\llcorner\mathbf{U}^{n}\left(x_{1}, d\right)\right\rangle\right. \\
& \leq \lambda^{2}\left\langle\Phi, T L \mathbf{U}^{n}\left(x_{1}, d\right)\right\rangle \leq \lambda^{3}\|T\| \mathbf{U}^{n}\left(x_{1}, d\right)<\delta .
\end{aligned}
$$

Set

$$
t=\langle\Psi, T\rangle-\langle\Psi, T+X\rangle .
$$

Then, by 2(5iv, v),

$$
\left\langle\Psi, h_{g(t) \#}(T+X)\right\rangle=\langle\Psi, T\rangle
$$


holds, so we have

$$
\left\langle\Phi, h_{g(t) \#}(T+X)\right\rangle \geq\langle\Phi, T\rangle .
$$

But also we have, again using 2(5iv, v)

$$
\begin{aligned}
\langle\Phi, & \left.h_{g(t) \#}(T+X)\right\rangle \\
& \leq\langle\Phi, T+X\rangle+\delta^{(1)}(T, \Phi, h) g(t)+c[g(t)]^{2} \\
& \leq\langle\Phi, T+X\rangle+\alpha\left(\beta^{-1} t+c t^{2}\right)+c\left(\beta^{-1} t+c t^{2}\right)^{2} .
\end{aligned}
$$

It follows that

$$
\begin{gathered}
|\beta|\langle\Phi, T\rangle \leq|\beta|\langle\Phi, T+X\rangle+\alpha(\langle\Psi, T+X\rangle-\langle\Psi, T\rangle) \\
+|\beta|(\langle\Psi, T+X\rangle-\langle\Psi, X\rangle|t|) \\
\cdot\left(\alpha c+\beta^{-2} c+2 c^{2}|\beta|^{-1}|t|+c^{3} t^{2}\right) .
\end{gathered}
$$

Consequently, we have

$$
\begin{gathered}
\langle\Xi, T\rangle \leq\langle\Xi \Xi, T+X\rangle+|\beta|(\alpha+|\beta|)^{-1}(\langle\Psi, T+X\rangle-\langle\Psi, T\rangle) \\
\cdot|t| \cdot 5(1+\alpha)(1+c)^{3}(1+\delta)^{2}\left(1+|\beta|^{-1}\right)^{2} .
\end{gathered}
$$

We note that

$$
\langle\Psi, T+X\rangle-\langle\Psi, T\rangle \leq\langle\Psi, T\llcorner K+X\rangle \leq \lambda \mathbf{M}[T\llcorner K+X]
$$

and

$$
|t| \leq \lambda^{3} \sup \left\{\|T\| \mathbf{B}^{n}(x, d): x \in \mathbf{U}^{n}\left(x_{0}, r_{1}\right)\right\}
$$

So we have

$$
\langle\Xi, T\llcorner K\rangle \leq\langle\Xi, T\llcorner K+X\rangle+\omega(d) \mathbf{M}[T\llcorner K+X] .
$$

Case II. Assume (**) holds. The argument used in this case is similar to that used in Case I. The difference is that we set

$$
t=\langle\Phi, T\rangle-\langle\Phi, T+X\rangle
$$

and consider

$$
h_{f(t) \#}(T+X) \text {. }
$$

5. Lemma. There exists $\mu>0$, which depends only on $m$ and $\lambda$, with the following property: For each $r_{2}>0$ there exists $c_{2}=c_{2}\left(r_{2}, T, m, \lambda\right)>0$ such that if $0<\rho \leq r_{2}$ and $x \in \operatorname{spt} T$ satisfies $\operatorname{dist}(x, B \cup \operatorname{spt} \partial T) \geq r_{2}$, then $\|T\| \mathbf{U}^{n}(x, \rho) \leq c_{2} \rho^{\mu}$ holds. 
Proof. Set $\mu=\lambda^{-2} m$. Let $r_{2}>0$ be given. Set $c_{2}=\mathbf{M}(T)\left(r_{2}\right)^{-\mu}$. Fix $x \in \operatorname{spt} T$ which satisfies $\operatorname{dist}(x, B \cup \operatorname{spt} \partial T) \geq r_{2}$.

Define $u: \mathbf{R}^{n} \rightarrow \mathbf{R}$ by setting

$$
u(z)=|z-x| .
$$

Define $v:\left\{\rho: 0<\rho \leq r_{2}\right\} \rightarrow \mathbf{R}$ by setting

$$
v(\rho)=\|T\| \mathbf{U}^{n}(x, \rho) .
$$

Define $H: \mathbf{R} \times \mathbf{R}^{n} \rightarrow \mathbf{R}^{n}$ by setting

$$
H(t, z)=x+t(z-x) \text {. }
$$

For $0<\rho<r_{2}$, set

$$
S_{\rho}=T \operatorname{LU}^{n}(x, \rho)+H_{\#}\left[\left(\mathbf{E}^{1}\llcorner\{t: 0 \leq t \leq 1\})\langle T, u, \rho+\rangle\right] .\right.
$$

By [PH; 1.4], for each $0<\rho<r_{2}$ we have either

$$
\langle\Psi, T\rangle \leq\left\langle\Psi, S_{\rho}\right\rangle \quad \text { or } \quad\langle\Phi, T\rangle \leq\left\langle\Phi, S_{\rho}\right\rangle \text {. }
$$

For $\mathcal{L}^{1}$ almost every $0<\rho<r_{2}$ we have

$$
\mathbf{M}\left[H_{\#}\left[\left(\mathbf{E}^{1}\llcorner\{t: 0 \leq t \leq 1\}) \times\langle T, u, \rho+\rangle\right]\right] \leq m^{-1} \rho v^{\prime}(\rho) .\right.
$$

We conclude that for $\mathcal{L}^{1}$ almost every $0<\rho<r_{2}$

$$
\lambda^{-1} v(\rho) \leq \lambda m^{-1} \rho v^{\prime}(\rho)
$$

and, hence,

$$
\lambda^{-2} m \rho^{-1} \leq(v(\rho))^{-1} v^{\prime}(\rho)
$$

holds. The conclusion of 5 is now easily obtained by integrating $(*)$.

6. THEOREM. Suppose $\Phi$ and $\Psi$ are class 2 elliptic integrands and $\psi_{0} \leq \psi<\psi_{1}$. If $T \in \Re_{m, A}(Z)$ satisfies

$$
\begin{gathered}
\operatorname{spt}(R-\partial T) \subset B, \quad\langle\Psi, T\rangle=\psi, \\
\langle\Phi, T\rangle=\inf \left\{\langle\Phi, S\rangle: S \in \Re_{m, A}(Z),\right. \\
\operatorname{spt}(R-\partial S) \subset B,\langle\Psi, S\rangle=\psi\},
\end{gathered}
$$

then the set of regular points is dense in

$$
(\text { Int } A \cap \operatorname{spt} T) \sim(B \cup \operatorname{spt} \partial T) .
$$

Proof. The theorem follows from 3, 4.2, 5 and the main result of [BE]. 


\section{REFERENCES}

[AF] F. J. Almgren, Jr., Existence and regularity almost everywhere of solutions to elliptic variationa problems with constraints, Memoirs Amer. Math. Soc., 165 (1976).

[BE] E. Bombieri, Regularity theory for almost minimal currents, Arch. Rat. Mech. Anal., 78 (1982), 99-130.

[PH] H. Parks, Elliptic isoperimetric problems, Indiana Univ. Math. J., 30 (1981), 937-958.

Received September 15, 1982.

OREGON STATE UNIVERSITY

Corvallis, OR 97331 


\section{PACIFIC JOURNAL OF MATHEMATICS \\ EDITORS}

Donald BaBBITT (Managing Editor)

University of California

Los Angeles, CA 90024

Hugo RossI

University of Utah

Salt Lake City, UT 84112

C. C. Moore and Arthur Ogus

University of California

Berkeley, CA 94720
J. DugundiI

Department of Mathematics

University of Southern California

Los Angeles, CA 90089-1113

R. FINN and H. SAMELSON

Stanford University

Stanford, CA 94305

\section{ASSOCIATE EDITORS}
R. ARENS
E. F. BECKENBACH
B. H. NeUMANN
F. WOLF
K. YoshidA (1906-1982)

\section{SUPPORTING INSTITUTIONS}

\author{
UNIVERSITY OF ARIZONA \\ UNIVERSITY OF BRITISH COLUMBIA \\ CALIFORNIA INSTITUTE OF TECHNOLOGY \\ UNIVERSITY OF CALIFORNIA \\ MONTANA STATE UNIVERSITY \\ UNIVERSITY OF NEVADA, RENO \\ NEW MEXICO STATE UNIVERSITY \\ OREGON STATE UNIVERSITY
}

\author{
UNIVERSITY OF OREGON \\ UNIVERSITY OF SOUTHERN CALIFORNIA \\ STANFORD UNIVERSITY \\ UNIVERSITY OF HAWAII \\ UNIVERSITY OF TOKYO \\ UNIVERSITY OF UTAH \\ WASHINGTON STATE UNIVERSITY \\ UNIVERSITY OF WASHINGTON
}

The Supporting Institutions listed above contribute to the cost of publication of this Journal, but they are not owners or publishers and have no responsibility for its content or policies.

Mathematical papers intended for publication in the Pacific Journal of Mathematics should be in typed form or offset-reproduced (not dittoed), double spaced with large margins. Please do not use built up fractions in the text of the manuscript. However, you may use them in the displayed equations. Underline Greek letters in red, German in green, and script in blue. The first paragraph must be capable of being used separately as a synopsis of the entire paper. In particular it should contain no bibliographic references. Please propose a heading for the odd numbered pages of less than 35 characters. Manuscripts, in triplicate, may be sent to any one of the editors. Please classify according to the scheme of Math. Reviews, Index to Vol. 39. Supply name and address of author to whom proofs should be sent. All other communications should be addressed to the managing editor, or Elaine Barth, University of California, Los Angeles, California 90024.

There are page-charges associated with articles appearing in the Pacific Journal of Mathematics. These charges are expected to be paid by the author's University, Government Agency or Company. If the author or authors do not have access to such Institutional support these charges are waived. Single authors will receive 50 free reprints; joint authors will receive a total of 100 free reprints. Additional copies may be obtained at cost in multiples of 50 .

The Pacific Journal of Mathematics is issued monthly as of January 1966. Regular subscription rate: $\$ 132.00$ a year (6 Vol., 12 issues). Special rate: $\$ 66.00$ a year to individual members of supporting institutions.

Subscriptions, orders for numbers issued in the last three calendar years, and changes of address should be sent to Pacific Journal of Mathematics, P.O. Box 969, Carmel Valley, CA 93924, U.S.A. Old back numbers obtainable from Kraus Periodicals Co., Route 100, Millwood, NY 10546.

The Pacific Journal of Mathematics ISSN 0030-8730 is published monthly by the Pacific Journal of Mathematics at P.O. Box 969, Carmel Valley, CA 93924. Application to mail at Second-class postage rates is pending at Carmel Valley, California, and additional mailing offices. Postmaster: Send address changes to Pacific Journal of Mathematics, P. O. Box 969, Carmel Valley, CA 93924.

PUBLISHED BY PACIFIC JOURNAL OF MATHEMATICS, A NON-PROFIT CORPORATION

Copyright $\odot 1984$ by Pacific Journal of Mathematics 


\section{Pacific Journal of Mathematics}

\section{Vol. 113, No. $2 \quad$ April, 1984}

Alan Adolphson, On the Dwork trace formula ...................257

Amos Altshuler and Leon Steinberg, Enumeration of the quasisimplicial

3 -spheres and 4-polytopes with eight vertices .................. 269

Kenneth R. Goodearl, Cancellation of low-rank vector bundles .......... 289

Gary Fred Gruenhage, Ernest A. Michael and Yoshio Tanaka, Spaces

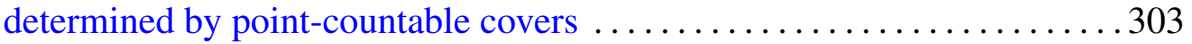

Charles Lemuel Hagopian, Atriodic homogeneous continua .......... 333

David Harbater, Ordinary and supersingular covers in characteristic $p$. . . 349

Domingo Antonio Herrero, Continuity of spectral functions and the lakes

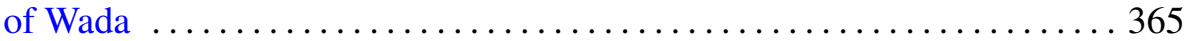

Donald William Kahn, Differentiable approximations to homotopy resolutions and framed cobordism ....................... 373

K. McGovern, On the lifting theory of finite groups of Lie type $\ldots \ldots \ldots . \ldots 383$

C. David (Carl) Minda, The modulus of a doubly connected region and the geodesic curvature-area method ............................. 395

Takuo Miwa, Complexes are spaces with a $\sigma$-almost locally finite base $\ldots . .407$

Ho Kuen Ng, Finitely presented dimension of commutative rings and modules

Roger David Nussbaum, A folk theorem in the spectral theory of

$C_{0}$-semigroups

J. S. Okon, Prime divisors, analytic spread and filtrations

Harold Raymond Parks, Regularity of solutions to elliptic isoperimetric problems

R. Sitaramachandra Rao and M. V. Subba Rao, Transformation formulae for multiple series

Daniel Ruberman, Imbedding punctured lens spaces and connected sums

Uri Srebro, Deficiencies of immersions 